Original Article

\title{
Effectiveness of Video Assisted Teaching Program on Knowledge Regarding Prevention and Management of Laryngitis among Primary School Teachers of Selected Primary Schools at Hassan
}

\author{
Mamatha B. ${ }^{1}$, Damayanthi S. $^{2}$ \\ ${ }^{1}$ Lecturer, Department of Medical Surgical Nursing, Nitte Usha Institute of Nursing Sciences, M angaluru - 575018, India, \\ ${ }^{2}$ Retd Professor \& H.O.D, Government College of Nursing, Hassan, India.
}

Corresponding author: Mamatha B., Lecturer, Department of Medical Surgical Nursing, Nitte Usha Institute of Nursing Sciences, Mangalore - 575 018, India. E-mail : mamathashetty68@yahoo.com

$\begin{array}{ll}\text { Received } & : 05.02 .2018 \\ \text { Review Completed } & : 13.03 .2018 \\ \text { Accepted } & : 25.04 .2018\end{array}$

Keywords: Effectiveness, VATP, Knowledge, Prevention, Laryngitis, Primary school teachers

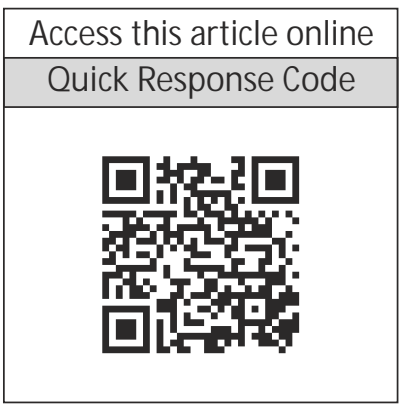

\begin{abstract}
Background: Teaching is a profession where teachers are exposed to use their voice excessively in many situations which impose the risk for developing morbidity caused to larynx, among them the most common is laryngitis. However, I felt that there was great need for educating primary school teachers on Prevention and Management of Laryngitis.
\end{abstract}

Objectives: To find the effectiveness of Video Assisted Teaching Program (VATP) on Knowledge regarding Prevention and $M$ anagement of Laryngitis among Primary School Teachers.

Material and Method: Quasi-experimental research design was adopted for the study with purposive sampling technique to select the sample $(N=60)$ with $n=30$ in experimental group and control group of primary school teachers respectively. A structured knowledge questionnaire was used to assess the Knowledge; VATP was administered only to experimental group to find its effectiveness in comparison with control group. The findings of the study revealed deficit in knowledge of primary school teachers before administration of VATP.

Results: The mean percentage knowledge score of post-test (79.80\%) was higher than the pretest (39.30\%). The calculated paired ' $t$ ' value is greater than the table value $(0.05,29 \mathrm{df})=2.045$. It showed a significant difference between mean pre and post- test knowledge scores among experimental group. The mean percentage of knowledge scores in post-test (79.80\%) among experimental group was higher than the post-test (39.80\%) among control group. The calculated unpaired ' $t$ ' value is greater than the table value $(0.05,58 \mathrm{df})=1.96$. Calculated $\chi^{2}$ values showed significant association between post-test knowledge scores of respondents with their selected demographic variables.

Conclusion: VATP was effective in increasing the knowledge of primary school teachers on Prevention and M anagement of Laryngitis.

\section{Introduction}

The more voice ergonomic risk factors found in the classroom the higher were the teachers. It has been shown that teachers are at high risk of developing occupational dysphonia in several countries. Teachers are unable to work due to voice problems more often than other occupational groups. Stress was the factor that correlated most strongly with voice symptoms. Poor indoor air quality increased the occurrence of laryngitis ${ }^{2}$.

A teacher with a vocal infection, who cannot speak loudly this shows teaching is displaying a form of limitation in the teaching activity. Screaming, shouting and loud speaking over a period of time and untreated chronic laryngitis produce edema of the vocal cords and the formation of nodules or polyps ${ }^{4}$. Chronic laryngitis, as the name implies, involves a longer duration of symptoms. Vocal misuse results in an increased adducting force of the vocal folds with subsequent increased contact and friction between the contacting folds. The area of contact between the folds becomesswollen.

Studies show that there is need to improve the knowledge on preventive measures against laryngitis; as teachers lack 
information and due to various stressful situations are not able to practice preventive measures. Imparting knowledge will improve knowledge and promote practice of preventive measures and undertake appropriate treatment measures to reduce complications associated with it to improve the quality of voice and health. In contrast to previous treatment, contemporary voice therapy is dynamic, including, general education (e.g., vocal anatomy and physiology, patient diagnosis, treatment options, and prognosis), establishing healthy vocal habits and identifying and avoiding vocally traumatic behaviors, and modifying voice production by training vocal techniques to alter vocal patterns that contribute or maintain the voice problem. A comprehensive approach with all these components is likely to yield superior outcomes.

\section{Materials and Methods}

Quasi Experimental research design with Control and Experimental groups was employed to evaluate the effectiveness of Video Assisted Teaching Program on Knowledge regarding prevention and management of laryngitis among Primary school teachers in selected Primary Schools at Hassan. Data collected from 60 Primary school teachers with 30 in Experimental and 30 in Control Groups.

Formal administrative permission was obtained from the Block Education Officer, Block Education Office, Hassan. The information regarding baseline data and knowledge questionnaire were administered asfollows:

Part-l: Age, Gender, Educational qualification, Religion, Family income, marital status, No. of. Children, Type of residence, Type of family, previous source of information or training program regarding prevention and management of laryngitis.

Part-II: Structured knowledge questionnaire consisted of 41 items on knowledge regarding Prevention and $M$ anagement of Laryngitis. It consists of eight aspects; the pre-test to assess the knowledge of 60 primary school teachers regarding Prevention and management of laryngitis at selected primary schools, Hassan. The purposes and objectives of the study were explained to Primary school teachers and confidentiality was assured with consent to participate in the study.

Administration of Video Assisted Teaching Program The video assisted teaching program on Prevention and management of laryngitis at selected primary schools was showed after pre-testing on the same day only for the experimental group.

Post test Post test was conducted on 8th day after pretesting and VATP to find out the effectiveness of video assisted teaching program in terms of increase in their knowledge by using knowledge questionnaire. All the participants co-operated well with the investigator in both pre-test and post-test.

The mean percentage knowledge score of post-test (79.80 $\%)$ was higher than the pre-test (39.30\%). The calculated paired' $t$ ' value is greater than the table value $(0.05,29 \mathrm{df})=$ 2.045. It showed a significant difference between mean pre and post- test knowledge scores among experimental group. The mean percentage of knowledge scores in posttest (79.80\%) among experimental group was higher than the post-test $(39.80 \%)$ among control group. The calculated unpaired' $t$ ' value is greater than the table value $(0.05,58 \mathrm{df})=1.96$. Calculated $?^{2}$ values showed significant association between post-test knowledge scores of respondents with their selected demographic variables.

\section{Results}

Findings Related to the Respondents Personal and Related Characteristics.

- Most of the primary school teachers (41.70\%) were aged between 41 - 50 years, 5538.30\% were aged between $31-40$ years and the remaining $20.00 \%$ were aged between 21-30 years.

- Most of the primary school teachers $(93.30 \%)$ were Females and remaining $6.70 \%$ were $M$ ales.

- Most of the primary school teachers $(90.00 \%)$ were married and rest $10.00 \%$ were Unmarried.

- Most of the primary school teachers (45.00\%) have two 
and more children, $35.00 \%$ had one child and remaining $20.00 \%$ had no children.

- Most of the primary school teachers $(41.70 \%)$ completed B.Ed course $33.33 \%$ completed PG course and remaining $25.00 \%$ completed D.Ed course.

- Most of the primary school teachers (76.70\%) were Hindus, $13.30 \%$ were Muslims and the remaining $10.00 \%$ were Christians.

- Most of the primary school teachers (76.70\%) were from Nuclear family and $23.30 \%$ were from Joint family.

- Most of the primary school teachers (96.70\%) were from urban areas and 3.30\% were from rural areas.

- Most of the primary school teachers family Income per month, (58.30\%) were more than Rs.20,001, 30.00\% were between Rs.15,001-20,000, 8.30\% were between Rs.10,001-15,000 and remaining 3.30\% were less than Rs. 10,000 .

- All, $100 \%$ of the primary school teachers had not attended Training Program on Prevention and Management of Laryngitis.

- Most of the primary school teachers (35.00\%) had no previous source of information, $31.70 \%$ received previousinformation through Electronic media,

- $25.00 \%$ received previous information through Health personnel and remaining $8.30 \%$ of the respondents received previous information through Family members

\section{Pre-test $\left(\mathbf{O}_{1)}\right.$}

Pre-test was conducted to assess the knowledge of 60 primary school teachers regarding Prevention and management of laryngitis at selected primary schools, Hassan.

The purposes and objectives of the study were explained to Primary school teachers and confidentiality was assured with consent to participate in the study.

Classification of Respondents Pre test knowledge level among Experimental and Control groups on Prevention and M anagement of Laryngitis

\begin{tabular}{|l|l|c|c|c|c|c|c|}
\hline Knowledge & Category & \multicolumn{5}{|c|}{ Respondents Group } \\
\hline \multirow{2}{*}{ level } & & $\begin{array}{c}\text { Experimental } \\
(\mathbf{n = 3 0 )}\end{array}$ & \multicolumn{2}{c|}{$\begin{array}{c}\text { Control } \\
(\mathbf{n = 3 0 )}\end{array}$} & $\begin{array}{c}\text { Combined } \\
(\mathbf{n = 6 0 )}\end{array}$ \\
\cline { 3 - 9 } & & $\mathbf{N}$ & $\%$ & $\mathbf{N}$ & $\%$ & $\mathbf{N}$ & $\%$ \\
\hline Inadequate & $\leq 50 \%$ Score & 25 & 83.30 & 25 & 83.30 & 50 & 83.30 \\
\hline M oderate & $51-75 \%$ Score & 5 & 16.70 & 5 & 16.70 & 10 & 16.70 \\
\hline Adequate & $>75 \%$ Score & 0 & 0.00 & 0 & 0.00 & 0 & 0.00 \\
\hline Total & & 30 & 100.00 & 30 & 100.00 & 60 & 100.00 \\
\hline
\end{tabular}

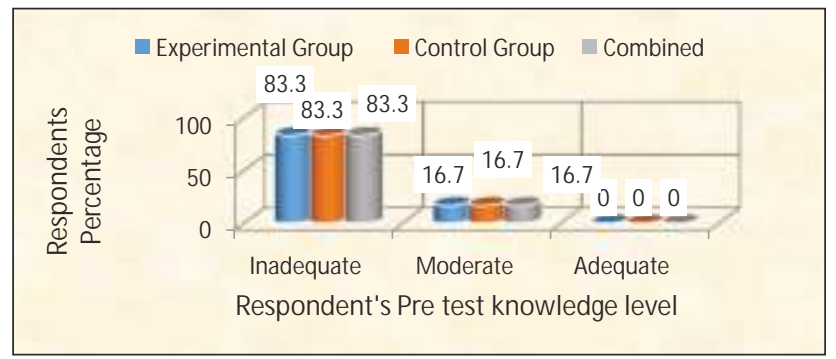

Distribution of respondents on Pre test Knowledge level

\section{Administration of Video Assisted Teaching Program}

The video assisted teaching program on Prevention and management of laryngitis at selected primary schools was showed after pre-testing on the same day only for the experimental group.

\section{Over all M ean Pre test and Post test knowledge Scores of} Experimental group on Prevention and Management of Laryngitis

\section{Posttest $\left(\mathbf{O}_{2)}\right.$}

Post test was conducted on $8^{\text {th }}$ day after pre-testing and VATP to find out the effectiveness of video assisted teaching program in terms of increase in their knowledge by using knowledge questionnaire. All the participants cooperated well with the investigator in both pre-test and post-test.

Experimental Group $\quad n=30$

\begin{tabular}{|l|c|c|c|c|c|c|}
\hline Aspects & $\begin{array}{l}\text { Max. } \\
\text { Score }\end{array}$ & \multicolumn{6}{|l|}{ Respondents Knowledge Scores } & $\begin{array}{l}\text { Paired } \\
\text { 't' Test }\end{array}$ \\
\hline & & Mean & SD & M ean (\%) & SD (\%) & \\
\hline Pre test & 41 & 16.13 & 3.00 & 39.30 & 7.20 & $27.05^{*}$ \\
\hline Post test & 41 & 32.73 & 3.00 & 79.80 & 7.30 & \\
\hline Enhancement & 41 & 16.60 & 3.40 & 40.50 & 8.20 & \\
\hline
\end{tabular}

*: Significant, 


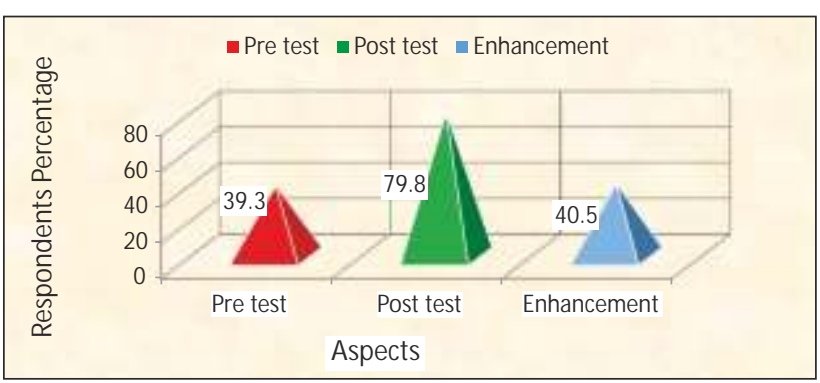

Distribution of overall Pre-Test and Post-Test knowledge scores of experimental group.

Classification of Respondent Post test knowledge level among Experimental and Control groups on Prevention and M anagement of Laryngitis $\quad \mathrm{N}=60$

\begin{tabular}{|c|c|c|c|c|c|c|c|}
\hline \multirow{3}{*}{\begin{tabular}{|l}
$\begin{array}{l}\text { Knowledge } \\
\text { Levels }\end{array}$ \\
\end{tabular}} & \multirow[t]{3}{*}{ Category } & \multicolumn{6}{|c|}{ Respondents Group } \\
\hline & & \multicolumn{2}{|c|}{$\begin{array}{c}\text { Experimental } \\
(\mathrm{n}=\mathbf{3 0})\end{array}$} & \multicolumn{2}{|c|}{\begin{tabular}{|c|} 
Control \\
$(n=30)$
\end{tabular}} & \multicolumn{2}{|c|}{$\begin{array}{c}\text { Combined } \\
(n=60)\end{array}$} \\
\hline & & $\mathrm{N}$ & $\%$ & $\mathrm{~N}$ & $\%$ & $\mathrm{~N}$ & $\%$ \\
\hline \begin{tabular}{|l} 
Inadequate \\
\end{tabular} & $\leq 50 \%$ Score & 0 & 0.00 & 25 & 83.30 & 25 & 41.66 \\
\hline Moderate & 51-75 \% Score & 11 & 36.70 & 5 & 16.70 & 16 & 26.67 \\
\hline Adequate & $>75 \%$ Score & 19 & 63.30 & 0 & 0.00 & 19 & 31.67 \\
\hline Total & & 30 & 100.00 & 30 & 100.00 & 60 & 100.00 \\
\hline
\end{tabular}

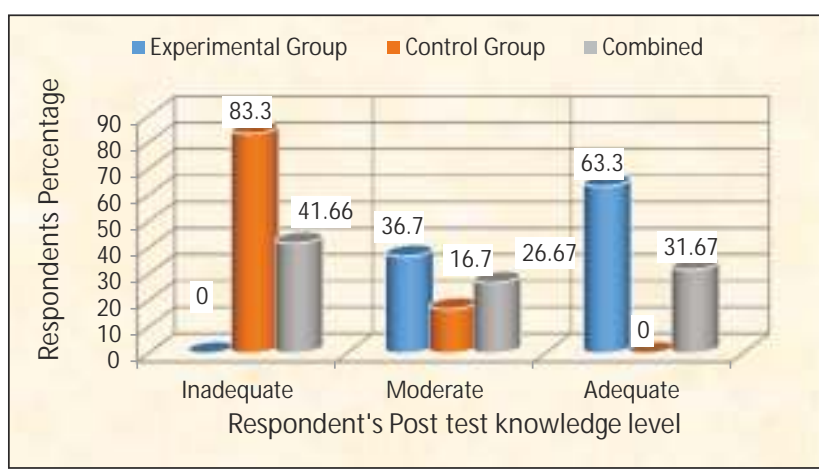

Distribution of respondents on Post test Knowledge level

Comparison of Overall mean post test knowledge scores of Experimental and Control groups on Prevention and Management of Laryngitis $\quad \mathrm{N}=60$

\begin{tabular}{|c|c|c|c|c|c|}
\hline \multirow[t]{2}{*}{ Group } & \multirow{2}{*}{$\begin{array}{c}\text { Sample } \\
\text { (n) }\end{array}$} & \multirow{2}{*}{$\begin{array}{l}\text { Max. } \\
\text { Score }\end{array}$} & \multicolumn{2}{|c|}{ Knowledge scores } & \multirow{2}{*}{\begin{tabular}{|c} 
Unpaired \\
't' Test
\end{tabular}} \\
\hline & & & \begin{tabular}{|l|} 
Mean (\%) \\
\end{tabular} & SD (\%) & \\
\hline Experimental & 30 & 41 & 79.80 & 8.0 & \multirow[t]{3}{*}{$20.23^{*}$} \\
\hline Control & 30 & 41 & 39.80 & 7.3 & \\
\hline \begin{tabular}{|l} 
Differenc \\
\end{tabular} & & & 40.00 & 7.33 & \\
\hline
\end{tabular}

*: Significant,

$t(0.05,58 d f)=1.96$

\section{Discussion}

Findings related to Effectiveness of Video Assisted Teaching Program

- Most of the respondents in both, in experimental group

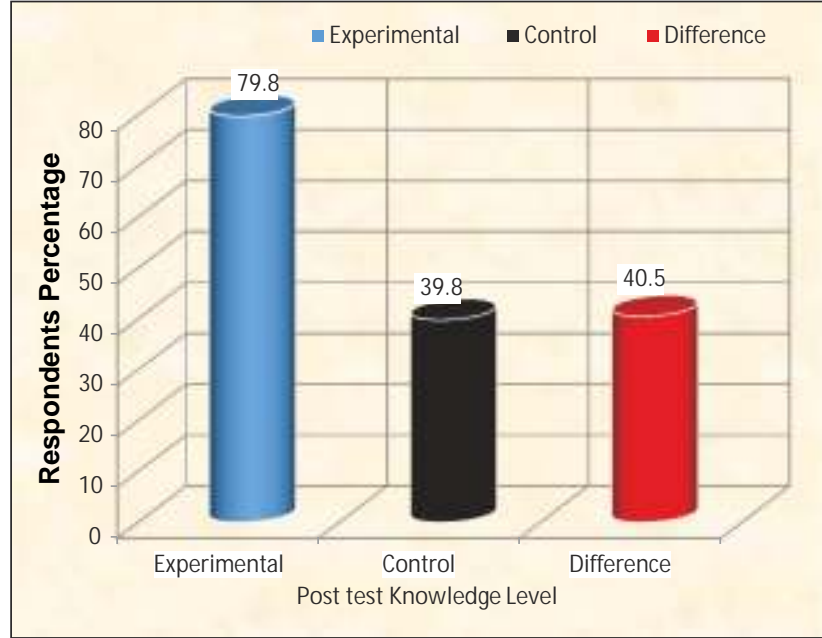

Distribution of Comparison of respondents Post test Knowledge level between Experimental and Control groups

Association of pre and post test knowledge levels of Experimental group on Prevention and Management of Laryngitis $n=30$

\begin{tabular}{|c|c|c|c|c|c|c|}
\hline \multirow[t]{3}{*}{\begin{tabular}{|l}
$\begin{array}{l}\text { Knowledge } \\
\text { Level }\end{array}$ \\
\end{tabular}} & \multirow[t]{3}{*}{ Category } & \multicolumn{4}{|c|}{$\begin{array}{c}\text { Classification of } \\
\text { Respondents }\end{array}$} & \multirow[t]{2}{*}{$\begin{array}{c}\chi^{2} \\
\text { Value } \\
\end{array}$} \\
\hline & & \multicolumn{2}{|c|}{ Pre test } & \multicolumn{2}{|c|}{ Post test } & \\
\hline & & $\mathrm{N}$ & $\%$ & $\mathrm{~N}$ & $\%$ & \\
\hline Inadequate & $\leq 50 \%$ Score & 25 & 83.30 & 0 & 0.00 & $46.25^{*}$ \\
\hline Moderate & $51-75 \%$ score & 5 & 16.70 & 11 & 36.70 & \\
\hline Adequate & $>75 \%$ Score & 0 & 0.00 & 19 & 63.30 & \\
\hline Total & & 30 & 100.00 & 30 & 100.00 & \\
\hline
\end{tabular}

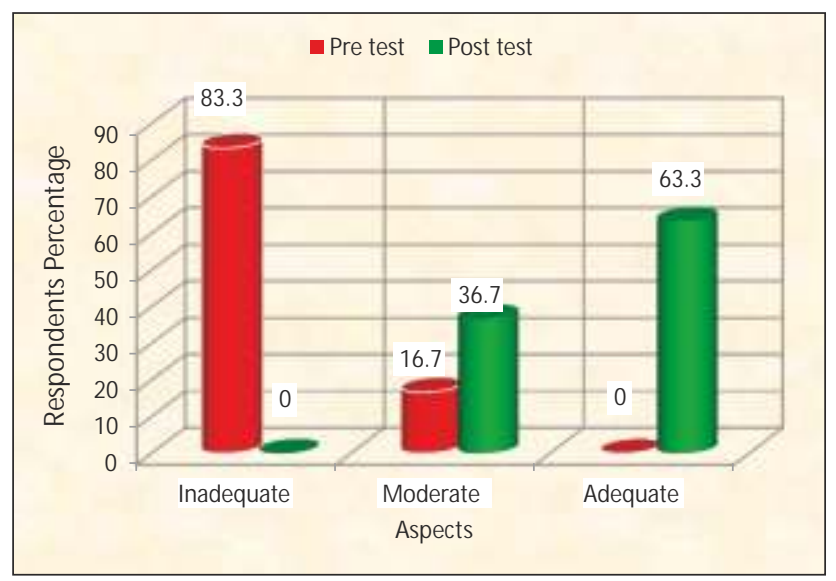

Distribution of Classification of Respondents Overall Pre test and Post test Knowledge level among Experimental group

and in control group (83.30\%) had inadequate knowledge and (16.70\%) of them had moderate knowledge in pre-test. In post-test majority of respondents, in experimental group (63.30\%) had 
adequate knowledge and (36.70\%) of them had moderate knowledge; but the post test knowledge level remained the same as the pre test knowledge level among the control group.

- The mean percentage knowledge scores of respondents in pre-test were maximum, $44.3 \%$ in the aspect of Signs, symptoms and Complications and minimum knowledge score of $20.00 \%$ in the aspect of Incidence and Prevalence of Laryngitis on Prevention and Management of Laryngitis among experimental group. The mean percentage knowledge scores of respondents in pre-test were maximum, $46.70 \%$ in the aspect of General information and minimum knowledge score of $22.20 \%$ in the aspect of Incidence and Prevalence of Laryngitis on Prevention and $M$ anagement of Laryngitis among control group.

- The mean percentage knowledge scores of respondents in post-test were maximum, $92.50 \%$ in the aspect of General information and minimum knowledge score of $62.20 \%$ in the aspect of Incidence and Prevalence of Laryngitis on Prevention and M anagement of Laryngitis among experimental group. The mean percentage knowledge scores of respondents in post-test were maximum, $47.50 \%$ in the aspect of General information and minimum knowledge score of $23.30 \%$ in the aspect of Incidence and Prevalence of Laryngitis on Prevention and $M$ anagement of Laryngitis among control group.

- The mean pre-test knowledge score of respondents was $39.30 \%$ and that of post-test was $79.80 \%$ with the enhancement of $40.50 \%$ among experimental group. The calculated paired ' $t$ ' $=27.05 *$ is greater than table value $(0.05,29 \mathrm{df})=2.045$, which shows that there is significant difference between pre-test knowledge score and post-test knowledge score among experimental group. Hence the research hypothesis $\mathrm{H}_{1}$ was accepted. Thus it suggests that the Video Assisted Teaching Program has been effective in increasing the knowledge of Primary school teachers regarding Prevention and Management of Laryngitis among experimental group.

- The calculated unpaired't' value (32.67) is greater than table value $(0.05,58 d f)=1.96$, which shows that there is significant difference in post-test knowledge scores between experimental group and control group. Hence the research hypothesis $\mathrm{H}_{2}$ was accepted. Thus it suggests that the Video Assisted Teaching Program has been effective in increasing the knowledge of Primary school teachers regarding Prevention and $M$ anagement of Laryngitis among experimental group.

\section{Findings related to association between post test level of} knowledge scores and selected demographic variables of Primary school teachers among experimental group.

- These findings indicated that age groups, educational status, religion, place of residence and family monthly income ? ${ }^{2}$ values were less than the table value at 0.05 level of significance. Therefore research hypothesis $\left(\mathrm{H}_{3}\right)$ is rejected. In the area of marital status, No. of. Children, type of family and previous source of information on Prevention and Management of Laryngitis, ? ${ }^{2}$ values were more than the table value at 0.05 level of significance, so research hypothesis $\left(\mathrm{H}_{3}\right)$ is accepted at 0.05 level of significance respectively.

\section{Recommendations}

- The study can be a replicated on a large sample.

- Similar study can be undertaken using other teaching strategies.

- Similar study can be conducted using larger number of samples selected by probability sampling for wider generalization.

- A comparative study can be conducted by administering VATP to samples of two different groups with different demographic variable.

- A Comparative study can be conducted to assess the practice of Primary school teachers on prevention and management of laryngitis.

- A Similar study can be conducted on different sample, different settings with different demographic variables.

\section{Conclusion}

\section{The following conclusions were drawn from the study}

- Adaptation of Preventive measures has positive effects on prevention and management of laryngitis. 
- The knowledge of the Primary school teachers was inadequate before the administration of VATP.

- There is significant difference between mean pre-test and post-test knowledge scores of Primary school teachers regarding Prevention and Management of Laryngitis.

- There is significant difference between mean post-test knowledge scores of experimental group and post-test

\section{References}

1. Laryngitis - Introduction (Serial online). NHS Choices Medical Reference Boots Web MD Partners in Health; 2009 [Updated 2012; cited on 2013 Dec 10]. Available from URL: http://www.webmd. boots.com/a-to-z-guides/tc/laryngitis-treatinglaryngitis

2. Rantala LM , Hakala SJ, Holmqvist S, Sala E. Connections between voice ergonomic risk factors and voice symptoms, voice handicap, and respiratory tract diseases. J.voice (serial online). 2012 Nov [cited on 2013 Dec 10]; 26(6):819. Epub 2012 Oct 6.Available from URL: http:// www.ncbi.nlm.nih.gov/pubmed/23044460

3. Arunachalam R, Boominathan P, M ahalingam S. Clinical Voice Analysis of Carnatic Singers. J.voice (serial online). 2013 Nov 22 [cited on 2013 Dec 10] (13)00153-7. Epub ahead of print 2013.08.003. Available from URL: http:// www.ncbi.nlm.nih.gov/pubmed/24275462

4. Yiu Em. Impact and prevention of voice problems in the teaching profession: embracing the consumers' view. J voice (serial online). 2002 Jun [cited on 2013 Dec10]16(2):215-28. Available from URL: http://www.ncbi.nlm.nih.gov/pubmed/3A215-224

5. Rahul K Shah. Acute Laryngitis Medscape (serial online). 1994-2013 [cited on 2013Dec12]. Available from URL: http://emedicine. medscape.com/article/864671-overview\#0199. knowledge scores of control group among Primary school teachers regarding Prevention and M anagement of Laryngitis.

- VATP is proved to be one of the effective teaching methods.

- There is significant association between selected demographic variables and post test knowledge scores

6. Joyce M Black, Jane Hokanson Hawks. Medical Surgical Nursing. 8th ed. UP (India): Elsevier Publishers; 2009.

7. David G. Hanson, Jack J. Jiang. Laryngitis from Reflux: Prevention for the Performing Singer. otolaryngology.voice.laryngitisfromreflux.pdf (serial online). 1998 June [cited on $2015 \mathrm{Feb} 19]$. Available from URL: http://ent.nm.org/uploads/2/4/3/7/24375049/ otolaryngology.voice . laryngitisfrom reflux.pdf.

8. Reveiz L, Cardona AF, Ospina EG. Functional dysphonia and benign vocal cord lesions in professional voice users (serial online). 2012 JanMar [cited on 2015 Feb 13] (1):21-6, Epub apr.2012. Available from URL: http://www.ncbi.nlm.nih.gov/pubmed/23743967

9. Branski R C, M urray T. Voice Therapy M edscape (serial online). 2008 [Updated 2011 Nov 30; cited on 2013Dec12]. Available from URL:emedicine.medscape.com/article/866712-overview

10. Villanueva-Reyes A. Voice disorders in the Metropolitan Area of San Juan, Puerto Rico: profiles of occupational groups. J. voice (serial online). 2011 Jan [cited on 2013 Dec 10]; 25(1):83-7. Epub 2009 Nov 2 Available from URL: http://www.ncbi.nlm.nih.gov/pubmed/ 19883991 